\title{
Exploration of model worker and talent cultivation function mechanism
}

\author{
Jingang Zhao \\ China Energy Engineering Group Zhejiang Thermal Power Construction Co., Ltd., Hangzhou, 310015, China
}

Keywords: Model worker, Guidance and demonstration, Talent cultivation, Transformation and upgrading.

\begin{abstract}
The new normal of China's economy has raised a lot of new requirements and subjects for enterprise's talent cultivation work. To realize industry transition and upgrading of Chinese economy from "made in China" to "created in China", it is urgent to further improve labor quality. On the basis of diligent labor and faithful labor, creative work should be stressed. Model worker is excellent representative of the working class, elite in the enterprise, and model of staffs. In the great practice of enterprise transition and upgrading, enterprise should energetically promoting spirit of model worker, and combine it with talent cultivation work, give full play to model worker's leadership and demonstrative function in talent cultivation, energetically promote talent cultivation, transformation and upgrading, and innovative development of enterprise.
\end{abstract}

\section{Enterprise transformation must energetically promote spirit of model worker}

Grand career requires for great spirit which comes from great people. Model workers are good examples of adhering to China road, carry forward Chinese spirit, and concentrate Chinese power, who set examples for people of all nationalities with high self-responsibility, excellent labor innovation, selfless struggle and contribution. "Dedication, first-class, hardworking and innovative, indifferent to fame and fortune, and willing to sacrifice", they have vividly explained socialist core values and they are valuable spiritual fortune and strong spirit strength. In April 28, 2015, President Xi Jinping pointed out in the meeting of celebrating International Worker's Day and commending national model workers and advanced workers, "Carrying forward four 4-pronged comprehensive strategic layout requires to give the masses a full scope to initiative and creativity." Meanwhile, he emphasized, "we must keep promoting spirit of model worker and spirit of labor, and gather strong power for China's economic and social development. Labor is human being's essential activity. Labor is glorious. Creating greatness is the important interpretation of the rule of human civilization and progress." In his addressing, President Xi Jinping has spoken highly of model workers' outstanding contributions to socialist modernization, fully affirmed spirit of model workers and labor spirit, and also raised definite requirements to promote spirit of model workers, labor spirit, and stimulating workers' creation enthusiasm from the high level of coordinating and promoting "four-prolonged" comprehensive strategic layout.

\section{Model worker's role in talent cultivation}

Model worker are the excellent representative of the working class, elites in the enterprise and the good examples of staffs. Their words and acts have widely influence and appeal among employee team.

\section{The guidance and demonstrative function of cultivating and implementing socialist core values}

Enterprise development requires for positive energy. The core of spirit of model worker is professional dedication, steadfast spirit and pioneering spirit. It is the centralized reflection of cultivating and implementing socialist core values. In talent cultivation, enterprises should earnestly 
implement the guideline of respecting labor, respecting knowledge, respecting talents and respecting creation by closely focusing on enterprise production and management, teach, guidance and stimulate all staffs with model workers, express spirit of model worker to every staff so that they compare for the better rather than for the bad, and give full play to their guidance and demonstrative function.

\section{Incubation function of talent cultivation}

Spirit of the craftsman to make perfection more perfect can be seen in model workers. During talent cultivation, enterprise should apply multiple forms of talent cultivation mechanism such as model worker innovation workshop, master and apprentice pairing, teamwork cooperation to tackle key problems, establish platforms for technical instruction, exchange and training, and give play to model worker's incubation role, develop model worker's unique function in professional construction, and promote to construct learning-oriented, skill-oriented, and innovation-oriented labor troop.

\section{Problem-solving function of innovation and benefit-making}

In the present era, model worker should have the "willing ox" spirit of hardworking and should have the innovative and problem-solving ability of "professional and skillful". A model worker can mobilize a team which then radiate the whole enterprise. In enterprise innovative development, especially in the reform of enterprise transformation and upgrading, enterprise should innovate the carrier construction of innovating scientific problem tacking, create the learning condition for model worker and employees, establish innovation and benefit-making exchange platform, construct innovation and benefit-making index system, and actively develop model worker's problem-solving role in innovation and benefit-making.

\section{Approaches to effectively develop model worker's function of talent cultivation}

To effectively develop model worker's function of talent cultivation, it requires us to study and implement the spirit of President Xi Jinping's series important speeches, keep carrying out Party's guideline of respecting labor, respecting knowledge, and respecting talents, respecting creation, energetically promote spirit of model worker, and prioritize developing model worker's function, establish the value orientation of "labor is the most glorious, labor is the most lofty, labor is the greatest and labor is the most beautiful", so that diligent work, faithful labor, and creative labor can become powerful spiritual resonance and stimulate flourishing labor creative vitality.

\section{Fully recognize the positive significance of promoting spirit of model worker, painstakingly create good atmosphere of labor glory and creation of great}

Energetically promoting spirit of model worker is the appeal of time. In the intricate era, various strengths are flowing. Some invade our body and erode our organs. But some support our healthy energy and build our body. Model workers are releasing the glowing positive energy to support us and help bodybuilding. The time calls for the spirit of model worker, and the time upholds the spirit of model worker. We must always energetically promote the spirit of model worker and gather positive energy for building socialism with characteristics.

Energetically promoting spirit of model worker is the strong voice of time. In the society that times produce heroes, various celebrities emerge endlessly and dazzle our eyes. It is bright and starry. Thus idolaters emerge at this time and fans like mushrooms after rain are thriving. Looking at the vast starry sky, the most real and dazzling stares are model workers whose achievements make us heartwarming with esteemed personalities.

Energetically promoting spirit of model worker is the need of the times. In such a great time of pursuing China dream, model workers are pioneers and coordinate of making China dream come true. In ancient times and modern eras with robot emerging endlessly, laborers' hard work is essential. Because of labor creation, we own historical glory and China has embraced G20 Hangzhou summit and other historic opportunities, and established one and another broad platform to show China dream. 


\section{Respect model worker, care for model worker, learn from model worker and strive to be model worker}

Have correct cognition of model worker and do not judge every word and action of model worker with perfect standard. Model worker should do everything, can do everything, and must take the lead. In a word, model workers should charge forward, otherwise, they are not real model workers. Above understanding is one-sided and incorrect. Model workers are not god but ordinary people with thoughts and personalities. We should promote spirit of model worker through promoting outstanding exemplary deeds of model workers, and should care for them without exaggerating model workers or even defying model workers to bring intangible pressure and spiritual fatigue to them. We should energetically promote model workers realistically with no exaggeration. Only in this way, the masses can learn from samples and trust model workers. Also, model workers can work steadfastly and feel ease in their heart.

\section{Actively construct model worker innovative workshop}

Constructing model worker innovative workshop is an effective way to energetically promote spirit of model worker and labor spirit, as well as the platform to inherit spirit of the craftsman. With model worker as the leader, establish model worker innovative workshop led by model worker, employees extensively participated, highlighting innovative function, with standardized and orderly management, and let the seed of innovation and benefit-making take root and sprout in this land, and let the craftsmanship of making perfection perfect be inherited and developed, effectively carry forward the demonstrative function of model worker innovative workshop, energetically promote the conversion and application of scientific innovation achievements, and promote the transformation of economic development mode so as to promote enterprise transformation and upgrading, and enhance enterprise to improve quality and efficiency.

Firstly, management should be standardized and orderly. During the process of constructing model worker innovative workshop, standardize management from organization, system, plan, and evaluation, and guarantee there are organizations (teams), leaders (leading role), plans in the beginning of the year, supervision in the process, and summary in the end of the year. Completely intensify operations management, and continuously improve job performance.

Secondly, intensify responsibility education. The example strength is infinite. Responsibility is reflected on model workers and conscientious performance is the shining point of spirit of model worker. During model worker innovative workshop construction, we need to strengthen responsibility education and integrate model worker's responsibility awareness into the bloodline of staff troop, implant into the bone marrow of staff troop, carry forward the "willing ox" spirit of model worker's devotion, hardworking and hardship bearing, and try to deepen and expand the influence of model worker innovative workshop.

Thirdly, emphasize innovation and benefit-making function. The essence of model worker innovative workshop is innovation and benefit-making. Innovation is the core of spirit of craftsmanship, the soul of craftsman. Benefit-making is the working pursuit of model workers, as well as the objective of performing social responsibility. On March $5^{\text {th }}$ 2016, Premier of the State Council Li Keqiang proposed in report on government work, "Encourage enterprises to carry out personalized customization, flexibility production, and cultivate the spirit of craftsmanship to make perfection perfect, increase variety, improve quality and create brand". On March $5^{\text {th }} 2017$, Li Keqiang emphasized again, "The soul of quality is inventiveness. We should energetically promote spirit of craftsman, cultivate craftsman culture profoundly, abide by professional integrity, advocate excellence, and consummate incentive mechanism, and cultivate more Chinese craftsmen, and create more world-famous "Chinese brands", promote Chinese economy into quality era."

Fourthly, projects and pressure must be offered. Model worker innovation workshop construction should be incorporated into enterprise development planning from strategic level to promote the construction with strategic concept. Enterprise should combine with features and functions of model worker innovation workshop and formulate research subject to model worker innovation workshop 
according to enterprise development requirement, ask model worker innovation workshop to think and study difficulties, hotspots, confusions and bottlenecks. Pressure can stimulate power. Get model worker shouldered with responsibilities and promote model worker innovation workshop to solidly carry out innovation work.

Fifthly, strengthen talent cultivation work. Model worker innovation workshop should strengthen innovation talent cultivation work, actively participate in education training, key competitions, school-enterprise cooperation, master and apprentice pairing, skill authentication and other talent cultivation work, elaborately plan and carry out "propagate, help, and mobilize" talent cultivation scheme, fully develop talent incubation function of model worker innovation workshop. Meanwhile, model worker innovation workshop should capture and spread new knowledge, especially pays attention to capture and spread workshop related new knowledge, and play an engine role in cultivating high level and high skill talents. Develop model worker innovation workshop into the incubator of improving employee troop quality, relay baton of inheriting spirit of model worker, and platform to stimulate enterprise development vitality. Transform model worker's role from "lights spot" to "paillette", talent cultivation from self-rotation to revolution, and spirit of model worker from "potted landscape" to "scenery".

Sixthly, model worker innovation workshop should focus on construction and maintain innovative vitality. In enterprises organizational structure, model worker innovation workshop is a virtual organization. On one hand, enterprise should establish work practice platform based on model worker innovation workshop, on the other hand, implement demonstration assistance measures, and provide skill practice activities for first-tier employees in model worker innovation workshop to improve service ability with job demonstration, and cultivate modern skilled talent in the industry, and build model worker innovation workshop into an important base for first-tier employee's job innovation and skill perfection. On the other hand, model worker innovation workshop should step out to learn lessons so as to help model workers to expand vision, absorb information, learn experience, enrich knowledge and improve self-ability so as to fully develop radiation effect of model worker innovation workshop, and highlight the advantages of model worker innovation workshop, and maintain model worker innovation workshop to be vigorous. Meanwhile, strengthen the evaluation and incentive for model worker innovation workshop, effectively mobilize model worker innovation workshop, continuously improve the construction quality of model worker innovation workshop, and truly build model worker innovation workshop to the education base to promote spirit of model worker, training base to improve staff troop quality, and innovation base to enhance enterprise development vitality.

Seventhly, enhance guidance and instruction. Enterprise cannot regard model worker innovation workshop as a vanity project. Instead, model worker innovation workshop should be treated as the innovative platform. Strengthen education mentally, gather positive energy, and encourage model workers. Enhance working guidance and come up with ideas to guide model workers. Provide financial support such as activity expenditure, standardize operation and support model workers. Labor union should intensify the operations management of model worker innovation workshop, make orderly arrangement of model information, team prospect, responsibility distribution and achievement exhibition for overall promotion.

Ideology of model worker has provide supportive function in historic trend. Their behaviors have led the times to go forward rapidly. Glories have passed and we are shouldered with missions. Responsibility and undertaking is the task for model workers and all staffs. Energetically promote spirit of model worker, cultivate and implement socialist core values, deepen organization culture construction, and continuously make organization culture construction become the "relay baton" of inheriting spirit of model worker, "innovation source" of job position, "treasure chest" of enterprise innovation and benefit-making, "incubator" of employees quality improvement, "direction indicator" of team vitality, and "think tank" of enterprise development. 


\section{References}

[1] Xin Changqing, Energetically promote time spirit of labor glory and creation of greatness---learn to implement President Xi Jinping's important address in national model worker commendation conference, QiuShi Magzine, the 10th period, 2015.

[2] Wang Zhenxu, Labor union organziaiton should develop active function in promoting "four-pronged" comprehensive strategy, Chinese Workers' Movement, the 4th period 2015.

[3] Xu Zhongliang, Thinking and practice of labor union model worker's management service work, Chinese Workers' Movement, the 6th period 2015.

[4] Lv Guoquan, Li Yi, Primary study on labor spirit. Chinese Workers' Movement, the 6th period 2015.

[5] Wang Yanping, Thinking on further developing model worker's function. Zhejiang Worker's Daily, the 4th edition, Sep 17th, 2011.

[6] Zhao Jingang, Studies on constructing and perfecting labor emulation incentive mechanism. Zhejiang Worker's Daily, the 4th edition, Oct 29th, 2007. 